\title{
HOME PRODUCTION AND THE RESIDENTIAL ELECTRIC LOAD CURVE
}

\author{
Daniel H. HILL \\ Survey Research Center, University of Michigan, Ann Arbor, MI 48104, USA
}

\begin{abstract}
Most recent works concerning time-of-day demands for electricity totally ignore home production. In this article we show that an understanding of the timing of household productive activities is crucial to an understanding of the residential electric load curve, and to an understanding of future responses to time-of-day, seasonal, or other marginal cost based electricity pricing strategies. We show that the timing of energy-intensive household activities can be modeled in terms of classical inventory adjustment proccsses. Thosc activities characterized by long re-order cycles are most likely to be shifted in response to time-of-day prices. Residential load curve data and data from the National Time Use Study suggest that economists have tended to underestimate the importance of water heating in affecting the load curve. Because of the relatively long re-order cycle of activities using hot water, and the possibility of timing the water heater, these activities should be quite responsive to well designed time-of-use rate structures, both in the short- and long-run.
\end{abstract}

\section{Introduction}

Unlike the telephone companies, electric utilities in the United States have traditionally avoided time differentiated rate structures [Shepherd (1966)]. Primarily because of the recent dramatic increases in the price of fuel, construction, and capital, but also because of concern for the future availability of fossil fuels, this stance is being re-evaluated. The utilities are investigating numerous load management strategies in order to find some method of modcrating the rate of growth of peak demands and, thereby, the rate of growth of required capacity. Time differentiated rate structures represent one such strategy. The government is also interested in reducing peak demands because these demands are generally met with petroleum or gas burning peaking capacity, while base loads are generally met with large scale coal, nuclear, or hydro capacity which is highly fuel efficient [Turvey (1968)]. Reductions in the utilization of fuel inefficient peaking capacity can relieve some of the pressure on scarce or uncertain energy sources.

This unprecedented interest of government and industry in load management has resulted in, among other things, the Department of Energy funding numerous rate design demonstration projects, some of which should yield data of sufficient quality for scientific analysis. At the same time, such groups as the Electric Power Research Institute are encouraging economists to investigate the phenomenon of time-of-use electricity demands in order that reasonable theoretical and statistical models will be available when the data 
are finally collected. To date, the Electric Power Research Institute has sponsored two large workshops focused on modeling time-of-day demand for electricity. These workshops have produced several theoretical and econometric models of household demand for electricity by time-of-day [EPRI $(1977 \mathrm{a})]$.

One deficiency in the resulting literature is the lack of appreciation of the role of home production (i.e., the process by which electricity is converted into useful outputs in the home) in determining the timing of electricity demands. The fact that electricity does not directly yield utility is not totally ignored, of course. For the most part, however, home production is recognized in these models only via the inclusion of some measure of the household's appliance stock as a statistical control. As a consequence, far too much effort has been devoted to such questions as whether a Transcendental Logarithmic Utility Function specification is superior to a Linear Expenditure Systems approach [see, for instance, Atkinson (1977, 1978), Taylor (1977), and Christensen and Caves (1978)], while very little has been done which provides guidance to researchers designing data collection efforts or actual rate structures. In the following pages we shall develop and test a model of the timing of home production activities which has implications for both of these issues. In the course of this development we shall concentrate on the implications of the theoretical framework with respect to the degree of responsiveness of various household production activities to time-of-day rates.

\section{Home production}

The lack of interest in home production in existing time-of-day electricity demand models stems from a failure to recognize the fact that while electricity is itself a relatively nun-storable commodity, it is used in the residential sector to produce intermediate goods which are, to varying degrees, storable. An example of such an intermediate good is a stock of clean clothing. Household utility is derived, in part, from consumption from this stock.

The home production process can be thought of as a combination of a transformation and an inventory adjustment process. The transformation process is generally a physical process which involves applying energy to an input material (e.g., applying heat to a steak) to change its physical characteristics in a desirable fashion. The inventory process involves storing the transformed material until its use is called for in order to meet the consumṕtion levels dictated by utility maximization. The nature of the optimal inventory policy is determined by the nature of the demand process and by the nature of three distinct types of cost - storage costs, shortage costs, and re-order costs. 
The nature of the demand process is strongly affected by household time preference. Institutionally determined work schedules as well as biologically related sleep and eating schedules are such that the level of household demand for consumption of home produced commodities will vary over the hours of the day and the days of the week. [See, e.g., Koenker (1978).]

If the various costs are convex in inventory space then the unevenness of demand is sufficient to insure that the optimal inventory policy is of the classical Ss type [Karlin and Arrow (1957)]. Such a policy involves allowing the inventory level to fall to some minimal level $s$ before re-ordering up to some maximal level $S$. Sufficient conditions for the cost structure to be convex are that the storage costs are a non-decreasing function of inventory level, the shortage costs are a non-increasing function of inventory level, and there are no net diseconomies of scale in re-ordering or fabrication.

In order to formalize these arguments we need first observe that while utility maximization calls for a given level of consumption $C_{j t}^{*}$ of each homeproduced good $j$ in each period $t$, the actual attainable level of consumption $C_{j t}$ is constrained by the level of inventories on hand $X_{j t}$. If inventories are below some critical value $X_{j t}^{*}$ consumption will be constrained to be less than optimal and shortage costs will be incurred. Thus, shortage costs can be expressed as

$$
\begin{aligned}
& \sigma\left(X_{j t}\right)=0 \quad \text { if } X_{j t} \geqq X_{j t}^{*}, \\
& =U\left(C_{j t}^{*}\right)-U\left(C\left(X_{j t}\right)\right) \text { if } X_{j t}<X_{j t}^{*} .
\end{aligned}
$$

Since $C_{j t}^{*}$ is the optimal level of consumption given the outcomes of all previous decisions and current conditions, $\sigma$ is non-negative. Diminishing marginal utility of consumption is sufficient to insure that these shortage costs are decreasing in $X_{j}$.

Storage of a good also entails costs. For small inventories these costs are likely to be small, and to consist primarily of the opportunity costs of the resources tied up in the inventory. ${ }^{1}$ At some very high levels of inventory $X_{j t}^{* *}$, however, stored commodities will be so numerous as to interfere with other home production processes and thereby cause deviations from optimal levels of consumption of other goods. Thus storage costs can be represented as

$$
\begin{aligned}
& \Sigma\left(X_{j t}\right)=0 \quad \text { if } X_{j t}<X_{j t}^{* *} \text {, } \\
& =U\left(C_{r t}^{*}\right)-U\left(C_{r t}\left(X_{j t}\right)\right) \text { if } X_{j t} \geqq X_{j t}^{* *},
\end{aligned}
$$

which, of course, increase with $X_{j r}$.

\footnotetext{
'In this analysis we shall assume that these opportunity costs are zero.
} 
Fabrication, or re-order, costs can have a fixed component and a variable component. Thus we can describe them (in utility units) as

$$
\begin{aligned}
& F_{j}\left(\Delta X_{j t}\right)=0 \quad \text { if } \quad \Delta X_{j t} \leqq 0, \\
& =B_{j}+f_{j}\left(\Delta X_{j t}\right) \text { if } \quad \Delta X_{j t}>0 .
\end{aligned}
$$

As long as $B$ is non-negative and $f$ is a non-decreasing function of $X_{j t+1}$ $-X_{j t}$, there are instantaneous economies of scale. The least cost inventory policy is to fabricate $j$ if

$$
B<\sigma\left(X_{j t}\right)
$$

While the optimal amount to re-order, $(S-s) \geqq\left(X_{j t}^{* *}-X_{j t}^{*}\right)$, is a more complex function of the cost structure, cost-minimizing households will produce at least up to the point where

$$
\frac{B}{\Delta X}<\frac{\mathrm{d}\left(f\left(\Delta X_{j t}\right)+\Sigma\left(X_{j t}+\Delta X_{j t}\right)\right)}{\mathrm{d}(\Delta X)} .
$$

Thus the household should not fabricate good $j$ at all during those periods when the inventory is greater than $X_{j t}^{*}$, if there are any fixed components of the re-order costs. When they do fabricate they should produce a discrete amount sufficient to amortize the fixed production cost component over a number of units.

There are a number of very useful implications of this framework. First, because electricity is used primarily in the fabrication process the demand for electricity in the home will be characterized by sharp discontinuities. Second, if a significant portion of the fixed re-order costs $B$ are energy costs, then, ceteris paribus, the longer the average re-order cycle the more likely the household will find it advantageous to shift fabrication from the peak price period to the off-peak price period.

To see this latter conclusion, it is best to consider an applied inventory problem. Let us consider laundry. Utility maximization implies an optimal, albeit, uneven rate of soiling clothing $C_{c t}^{*}$. The rate of depletions of the stock of clean clothes is not, however, totally deterministic since accidents $E_{c t}$ do happen which tend to speed up the soiling process. Thus the rate of inventory depletion can be expressed as

$$
X_{\mathrm{ct}}-X_{\mathrm{ct}-1}=C_{c t}^{*}+E_{c t} \text {. }
$$

This rate as well as the minimal level of clothing stocks consistent with optimal consumption, $X_{c t}^{*}$, can be assumed to be directly proportional to the 
number of people in the home, since each member of the household soils clothes, and inversely proportional to the age of the younger members of the household, since the young ones have more accidents.

The maximum level of inventories beyond which storing clothes begins to affect other household production processes can be assumed to be directly proportional to house size, or more precisely number of closets and other storage areas.

The fabrication costs depend crucially on whether the long-run optimization outcome has resulted in the ownership of a clothes washer and/or dryer. This decision has been shown repeatedly to be affected by household demographics in predictable ways. Given access to a clothes washer and/or dryer the fixed portion of the fabrication costs are of three types - time costs, energy costs and materials costs. These costs are relatively fixed up to at least one full load of clothes and beyond that are simple multiples of one load levels. The variable costs are relatively small compared to the fixed costs and are primarily the time costs of sorting and folding clothes, but for households who use electric dryers also include a small energy cost in that the more clothes there are per load the more water there is to evaporate. It is fairly safe to assume that the clothes are not ironed.

The small shortage and storage costs and the large fixed component of the fabrication costs imply an optimal laundry policy characterized by infrequent re-ordering and large inventories.

In deciding whether to postpone laundry so as to take advantage of timeof-day rates, the appropriate decision rule at time ' $n$ ' is to do so if and only if

$$
\lambda_{\mathrm{ST}}\left(P_{e p}-P_{e o p}\right) E>\sum_{i=n}^{T} \sigma\left(X_{c t}\right)>B,
$$

where $\lambda_{s T}$ is the marginal utility of discretionary income at the time laundry is actually done, $P_{e p}$ and $P_{e o p}$ are the prices of peak and off-peak electricity, respectively, and $E$ is the total amount of electricity consumed by the laundry process. ${ }^{2}$

This decision rule has a number of implications. They are:

(1) The probability of shifting a discrete load in response to time-of-day pricing is inversely proportional to the shortage (and storage costs) and directly proportional to both the price differential and the amount of electricity consumed by the household activity.

(2) If the time differentiated rates are of the form where there are only two rate levels, an on-peak and an off-peak price, then problems with 'wandering' peaks are likely to result. The reason that there are no

\footnotetext{
${ }^{2} \mathrm{An}$ analogous rule can be constructed for the decision to do the laundry before inventories reach $X_{j}^{*}$ in order to take advantage of lower off-peak prices.
} 
advantages to, and continued shortage costs associated with, waiting for several hours after the off-peak prices go into effect and hence it is optimal to shift large discrete loads to the period immediately following the peak pricing periods. This provides a rationale for charging intermediate shoulder rates in the periods immediately adjacent to the peak rate period.

(3) Because the shortage costs accumulate over time whereas the benefits resulting from shifting the load to the off-peak period are realized only once, the probability that the household will find it advantageous to shift loads will be inversely related to the length of time that the peak period prices are in effect (more precisely, the greater the time over which nonoptimal inventories of clean clothes must be held to take advantage of off-peak prices, the less likely the household will find it advantageous to deviate from the decision rule which would be followed in the absence of time-differentiated pricing).

(4) Because the advantages of shifting loads are determined on the basis of the instantaneous marginal utility of expenditure at the time the activity is actually performed (rather than the time when inventories reach reorder points), the probability that a particular time-of-day pricing strategy will yield shifts in time-of-day demand in the short-run depends on the time of day that the peak prices cease to be in effect (or go into effect). During the waking hours when household members are at home the instantaneous marginal utility of expenditures $\left(\lambda_{s}\right)$ is likely to be highest. Thus time differentiated rates are likely to be more effective in shiftirg loads if the prices change when people are actively in the process of producing home commodities.

Table 1 presents cost components and implied inventory levels and reorder intervals for several household activities. Based on this a priori information we would expect clothes washing, dish washing, and house cleaning to be most responsive to time-of-day electricity rate structures since the re-order intervals are long. Since the storage costs of lighting are so large we would not expect any shifting of these loads in response to time-of-day rates. This does not rule out the possibility that high rates during the hours of darkness will result in reductions in these loads, but this reduction would represent a peak saving without a concomitant valley filling.

There are important details related to each activity which cannot be adequately summarized in a table such as presented in table 1 , but which should be considered when trying to explain household demand in response to time-of-day rates. Households ownirig a dishwasher, for instance, must choose between two distinct technologies in dish washing (using the machine or washing the dishes by hand). The re-order costs depend crucially on which technology is chosen because the machine has large instantaneous 
Table 1

Inventory cost components and implied re-order intervals.

\begin{tabular}{|c|c|c|c|c|c|}
\hline Activity & $\begin{array}{l}\text { Shortage } \\
\text { cost }\end{array}$ & $\begin{array}{l}\text { Storage } \\
\text { costs }\end{array}$ & $\begin{array}{l}\text { Re-order } \\
\text { costs }\end{array}$ & $\begin{array}{l}\text { Implied } \\
\text { inventory }\end{array}$ & $\begin{array}{l}\text { Implied } \\
\text { re-order } \\
\text { interval }\end{array}$ \\
\hline $\begin{array}{l}\text { Clothes } \\
\text { washing }\end{array}$ & $\begin{array}{l}\text { Moderate \& } \\
\text { increasing }\end{array}$ & Small & $\begin{array}{l}\text { Large fixed } \\
\text { component }\end{array}$ & Large & Long \\
\hline $\begin{array}{l}\text { Dish } \\
\text { washing }\end{array}$ & $\begin{array}{l}\text { Moderate \& } \\
\text { increasing }\end{array}$ & Small & $\begin{array}{l}\text { Large fixed } \\
\text { component } \\
\text { dependent } \\
\text { on mode }\end{array}$ & Moderate & $\begin{array}{l}\text { Moderate } \\
\text { to long }\end{array}$ \\
\hline $\begin{array}{l}\text { House } \\
\text { cleaning }\end{array}$ & Small & Very small & $\begin{array}{l}\text { Moderate fixed } \\
\text { component }\end{array}$ & Moderate & Moderate \\
\hline $\begin{array}{l}\text { Air } \\
\text { conditioning }\end{array}$ & $\begin{array}{l}\text { Moderate \& } \\
\text { increasing }\end{array}$ & $\begin{array}{l}\text { Moderate \& } \\
\text { increasing }\end{array}$ & $\begin{array}{l}\text { Small fixed } \\
\text { component }\end{array}$ & Small & Short \\
\hline Heating & $\begin{array}{l}\text { Moderate \& } \\
\text { increasing }\end{array}$ & $\begin{array}{l}\text { Moderate \& } \\
\text { increasing }\end{array}$ & $\begin{array}{l}\text { Small fixed } \\
\text { component }\end{array}$ & Small & Short \\
\hline Refrigeration & Very large & Small & $\begin{array}{l}\text { Small fixed } \\
\text { component }\end{array}$ & Small & Short \\
\hline Lighting & Moderate & Infinite & $\begin{array}{l}\text { Zero fixed } \\
\text { component }\end{array}$ & Zero & Zero \\
\hline Cooking & Large & $\begin{array}{l}\text { Moderate \& } \\
\text { increasing }\end{array}$ & $\begin{array}{l}\text { Large fixed } \\
\text { component }\end{array}$ & Moderate & Moderate \\
\hline
\end{tabular}

economies of scale. The situation is further complicated by the fact that there are specialized cooking and eating dishes. These factors suggest that an optimal adjustment process might involve doing a few dishes (of the type that have the lowest instantaneous inventory) by hand whenever shortages are acute, and saving the rest to be done with the machine during off-peak pricing periods.

It may come as a surprise that heating, air conditioning, and refrigeration are home-production activities which can be fruitfully analyzed in terms of inventory adjustment processes. The discrete re-ordering (compressor and burner cycling) in these activities differs from that encountered in other activities only in so far as manufacturers have automated the decision rule outlined in (4) above. The demand or inventory depletion process, of course, differs from activity to activity, as well as do the costs. In the case of clothes and dish washing utility maximization dictates the optimal rate of depletion of inventories while in the case of air conditioning and heating utility maximization dictates the optimal level of inventories and depletion is detcrmined by ambient weather conditions and the encrgy physics of the housing structure. ${ }^{3}$ Because both the energy required to heat (cool) the

${ }^{3}$ If simple thermal conduction is the primary advective process then the time rate of inventory 
structure and the amount of heat being conducted out of (back into) the structure increase linearly with the inside/outside temperature differential, the total amount of energy required to maintain a pleasant temperature increases with the square of the differential.

\section{Data and analysis}

In the fall of 1975 the Survey Research Center of the Institute for Social Research of The University of Michigan began collecting detailed information on the time-use patterns of a representative sample of U.S. adults (and their spouses). These same individuals were re-interviewed three times during 1976. The survey methodology employed to obtain this information was 'diary' methodology, where the respondents (and their spouses) were asked about yesterday's activities. Data from this study can be used to obtain proportions of adults in households engaged in various activities by time of day. Fig. 1 presents such information for two energy-intensive residential activities, cooking and dishwashing, during weekdays.

As fig. 1 indicates both cooking and dishwashing have three distinct peaks during the day. The breakfast peak occurs in the hour ending at 8 a.m. (i.e., 0700 to 0759 ) while the breakfast clean-up peaks slightly there-after. The noon or lunch peak occurs in the hour ending at 1 p.m. (i.e., 1300 hours) and is smaller than either the breakfast or supper peaks. The supper cooking peak, which occurs between 5 p.m. and 7 p.m. (1700 hours and 1900 hours) is more pronounced than either of the other peaks and is followed by the largest flurry of dishwashing activity of the day. It is interesting to note that it is only in the hours immediately following the evening meal that the proportion of households reportedly engaged in dishwashing exceeds that engaged in meal preparation. What this means is that even in the absence of time differentiated rate structures for energy inputs, households are willing to defer dishwashing activities until (presumably) their stock of clean dishes has reached a critical low level.

In terms of the theoretical arguments presented in the preceding pages, the mere fact that the total number of reports of dishwashing is far smaller than that of meal preparations, coupled with the fact that each meal results in some dirty dishes, implies that the re-order cycle for dishes is longer in

depletion is given by

$$
T=\gamma Q_{\text {out }}=\gamma c A\left(T_{\text {out }}-T_{\text {in }}\right) / d,
$$

for cooling when the air conditioner compressor is off. $T$ is the time rate of change of temperature, $\gamma$ is the specific heat of the house, $Q$ is the rate of conduction in calories per second, $c$ is the coefficient of thermal conduction, $A$ is the surface area of the house, $d$ is the thickness of the conduction surfaces, and $\left(T_{\text {out }}-T_{\text {in }}\right)$ is the temperature difference between the inside and outside. 


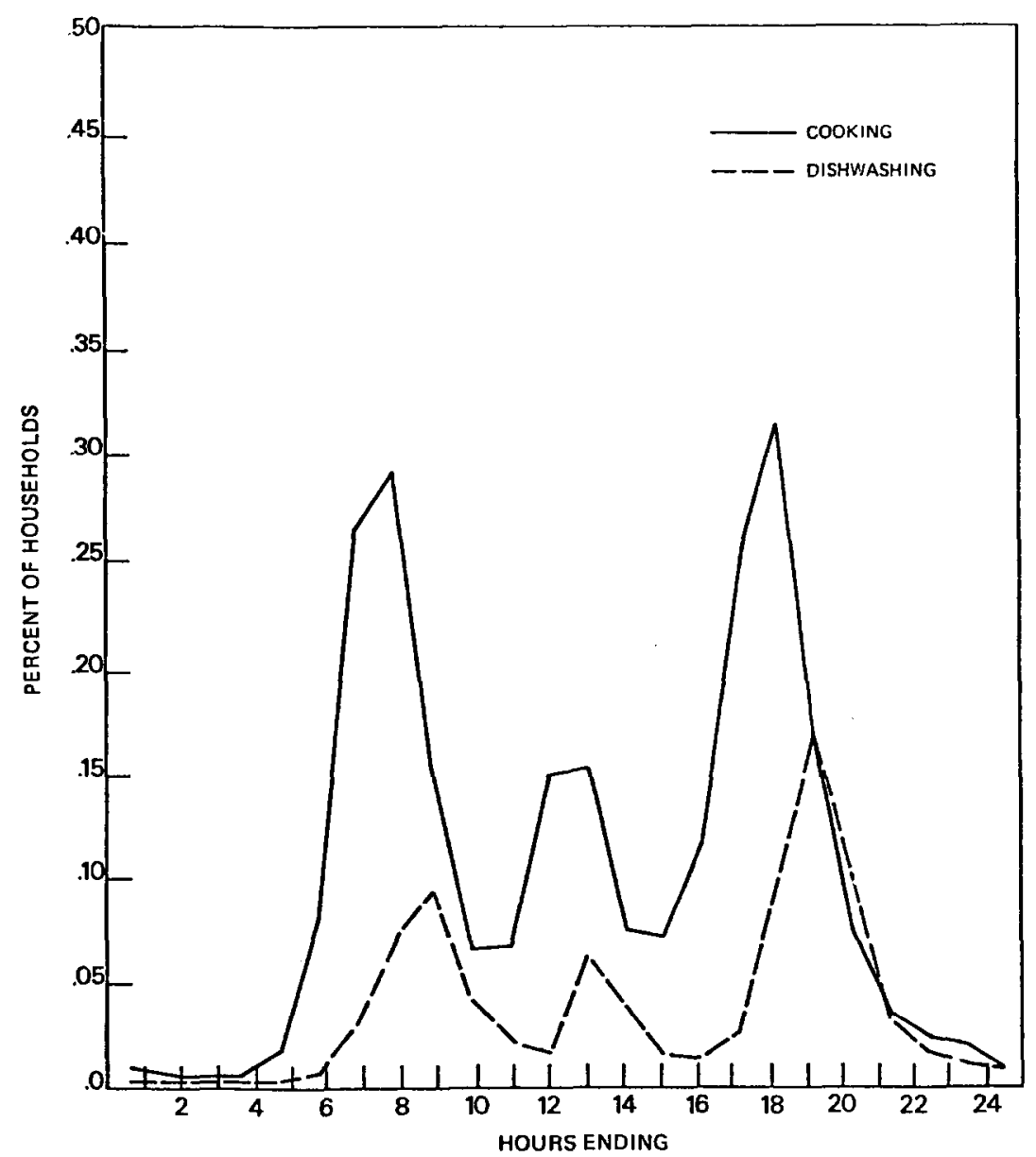

Fig. 1. Cooking and dishwashing.

duration than is the re-order cycle for meals. Since each of these activities involves rather substantial energy inputs, this in turn implies that we would expect dishwashing to be more responsive to time-differentiated rate structures than cooking.

Because there are substantial variations in the amount of time and energy devoted to the various meals of the day, the proportion of households preparing meals at some time during each hour is not a very accurate indicator of the electrical cooking loads by time of day. A cooking load index which is the product of average time spent in meal preparation by time-of-day, and the proportion doing some cooking in each hour can be constructed from the time-use data. Since the evening weekday meal is on 
average more elaborate than either breakfast or lunch, this index will be highest for supper.

Before going on to other energy-intensive home activities, it should be noted that the actual electricity demands from any activity involving substantial inputs of hot water are likely to be most intensive during the hour preceded by the activity itself. The reason for this is that electric hot water heaters take time to recover. A typical hot water heater with a single 2500 watt element requires approximately 79.6 minutes to heat fifteen gallons of water to standard temperatures (140 degrees Fahrenheit assuming an inlet water temperature of 50 degrees). A typical electric clothes washer, by contrast, draws less than 1000 watts and runs for only about 25 minutes per load. It uses anywhere up to 20 gallons of hot water.

Because of the large amounts of hot water employed in clothes washing it is an important component of home energy behavior. Fig. 2 presents the time-of-day profile of clothes-washing activities during weekdays. The percent of households where either the respondent or spouse reported being engaged in clothes washing activities peaks during the hour preceding $10 \mathrm{a} . \mathrm{m}$., and gradually declines throughout the day. There are slight increases after each of the other two meal clean-ups, but the general pattern is for clothes washing to be done early in the day. For households without automatic clothes dryers this pattern makes the most sense, in that it is important to get the clothes on the line while there is still enough sunlight to dry them. Most households, however, have automatic clothes dryers and therefore this may not be the explanation.

The relatively low level of the clothes-washing profile indicates that clothes washing is indeed an activity which can be characterized as having a long reorder cycle, and is therefore an activity which is likely to be highly responsive to time-differentiated rate structures.

The dashed line in fig. 2 represents the percentage of primary adults in households engaged in housecleaning activities at each hour of the day. Aside from the occasional use of electric vacuum cleaners, and some use of hot water, housecleaning is not an activity requiring large inputs of nonhuman energy. What is notable about this profile is its general similarity in shape to that of clothes washing. Its level is somewhat higher, indicating more frequent re-ordering, but for the most part it tracks clothes washing rather closely. It would appear from these two activity profiles that house work' other than cooking and dishwashing is a morning activity that tapers off in early afternoon.

A second activity which involves substantial inputs of energy in the form of hot water is bathing. Fig. 3 presents the diurnal pattern of bathing for adults in households during weekdays. The profile is quite peaked with most respondents and spouses bathing early in the morning. There are, in addition to this global early morning peak, smaller peaks occurring between 5 p.m. 


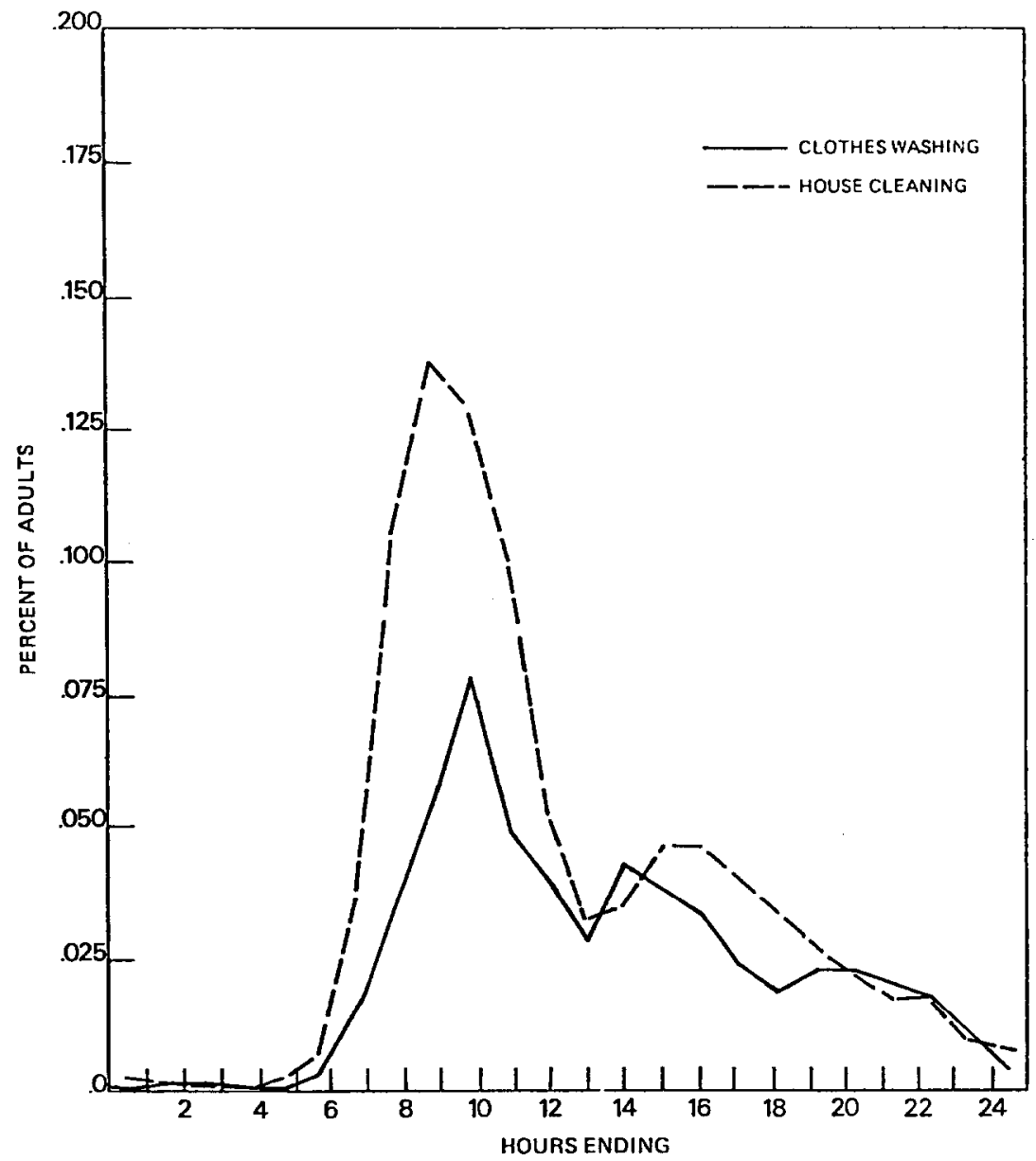

Fig. 2. Clothes washing and house cleaning (average weekday).

and 7 p.m. and between 11 p.m. and midnight. These secondary peaks appear to occur because some people bathe both before and after work, or before and after sleep, rather than because some people bathe in the mornings rather than evenings. It is difficult to speculate on the responsiveness of bathing activities to time-of-day energy rates. Certainly sufficiently high on-peak rates would encourage some reductions in the number of baths taken, and in the amount of water used per bath, during peak hours but it is probably true that most people exercise strong time preference with respect to when they bathe.

Before attempting to assess the relative importance of each of these activities in determining the residential load curve we must consider a class 


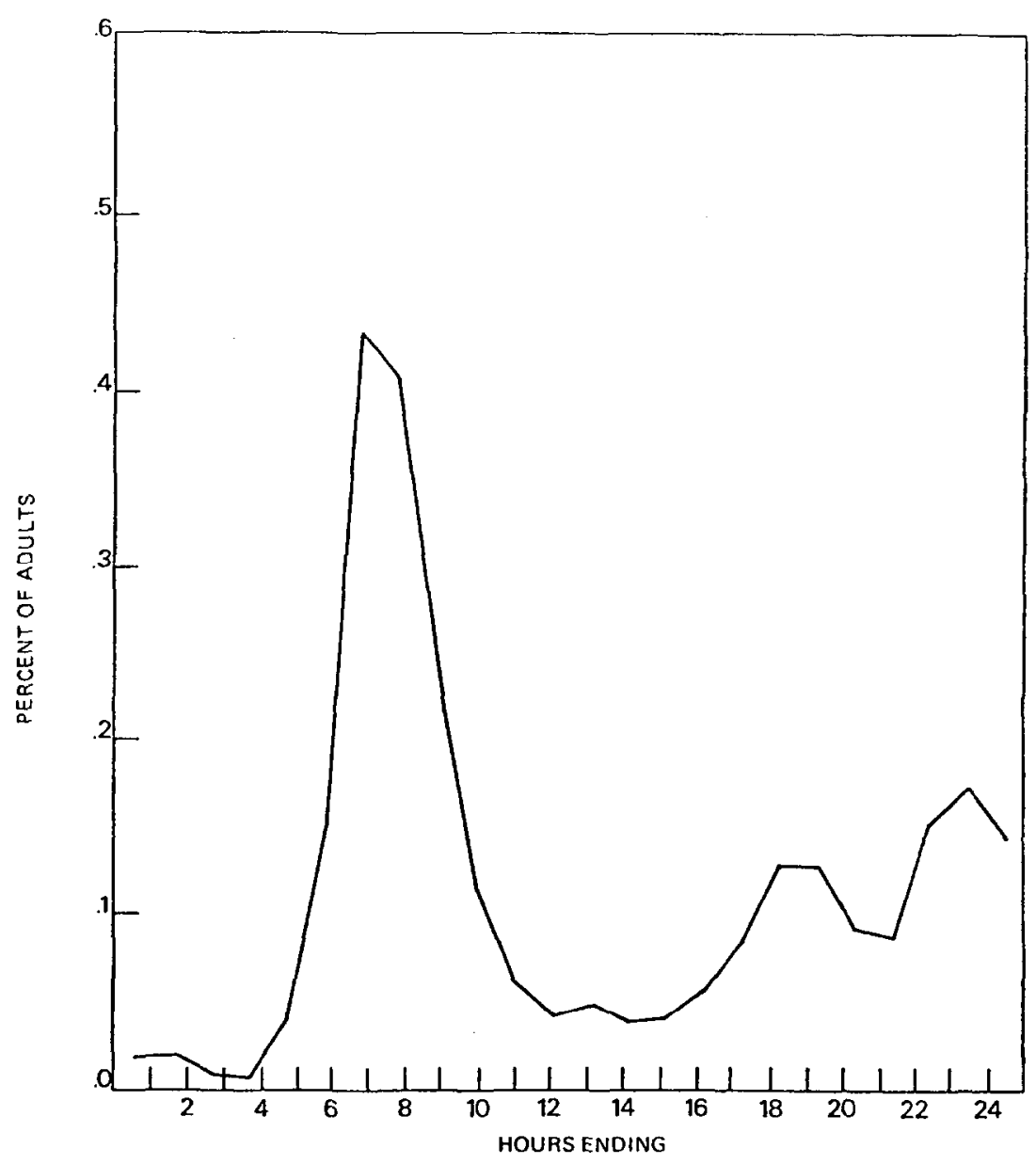

Fig. 3. Bathing (average weekday).

of home production activities which fall under the general heading of space conditioning and lighting. Space conditioning consists of heating and cooling the residential structure. Unfortunately data on the timing of loads for these activities is not available in the Time-Use Study. Since in the following section of this article we will want to relate the timing of loads for all major types of home production activities to an observed residential load curve (one for an average June weekday for a Northeastern utility) we must obtain the information needed to infer the temporal pattern of space conditioning and lighting from other sources.

Here we look to meteorological data. Fig. 4 presents the average dry-bulb temperature by hour of day for June in New York's Central Park. The 
temperature reaches its daily low in the hour preceding $6 \mathrm{a}$ a.m. and attains its high in the hour ending at 3 p.m. As was argued in the preceding section on home production, under the assumption that simple conduction is the primary advective process involved in depleting inventories of heat or its absence the electrical cooling loads should be directly proportional to the square of temperature above the optimal interior temperature. Since we will be concerned primarily with summer load patterns for the residential sector we need not concern ourselves here with heating loads.

Thus, the final load for which we need temporal data is lighting. During June in the Northeastern United States, the sun sets at approximately 8.30 p.m. and rises at approximately 5.30 a.m. Additionally at the latitude of

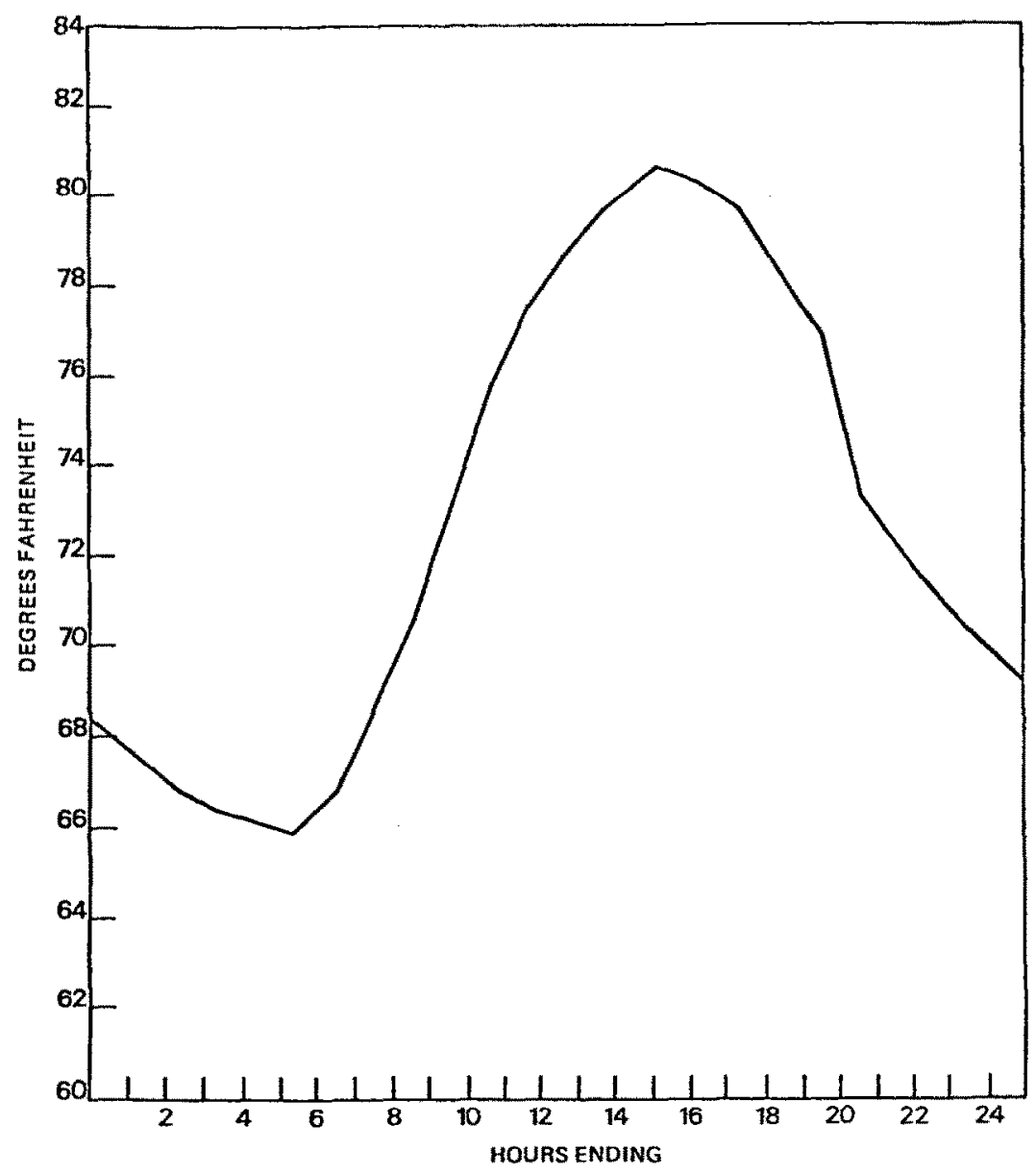

Fig. 4. Temperature. 
Hartford, Connecticut, the twilights are approximately one-and-a-half hours long. Based on these facts, the dashed line in fig. 5 represents what we shall call a darkness index and a measure of wakeful residential occupancy. This latter measure, derived from the Time-Use Study, is the percent of respondents at home but not sleeping by time-of-day, and is depicted by the dotted line in fig. 5. The solid line in fig. 5 represents our index of lighting needs. This index remains constant at zero during the daylight hours and climbs rather steeply after sunset to attain its maximum at about 10 p.m. As a result of pcople going to sleep, the index falls swiftly after 11 p.m.

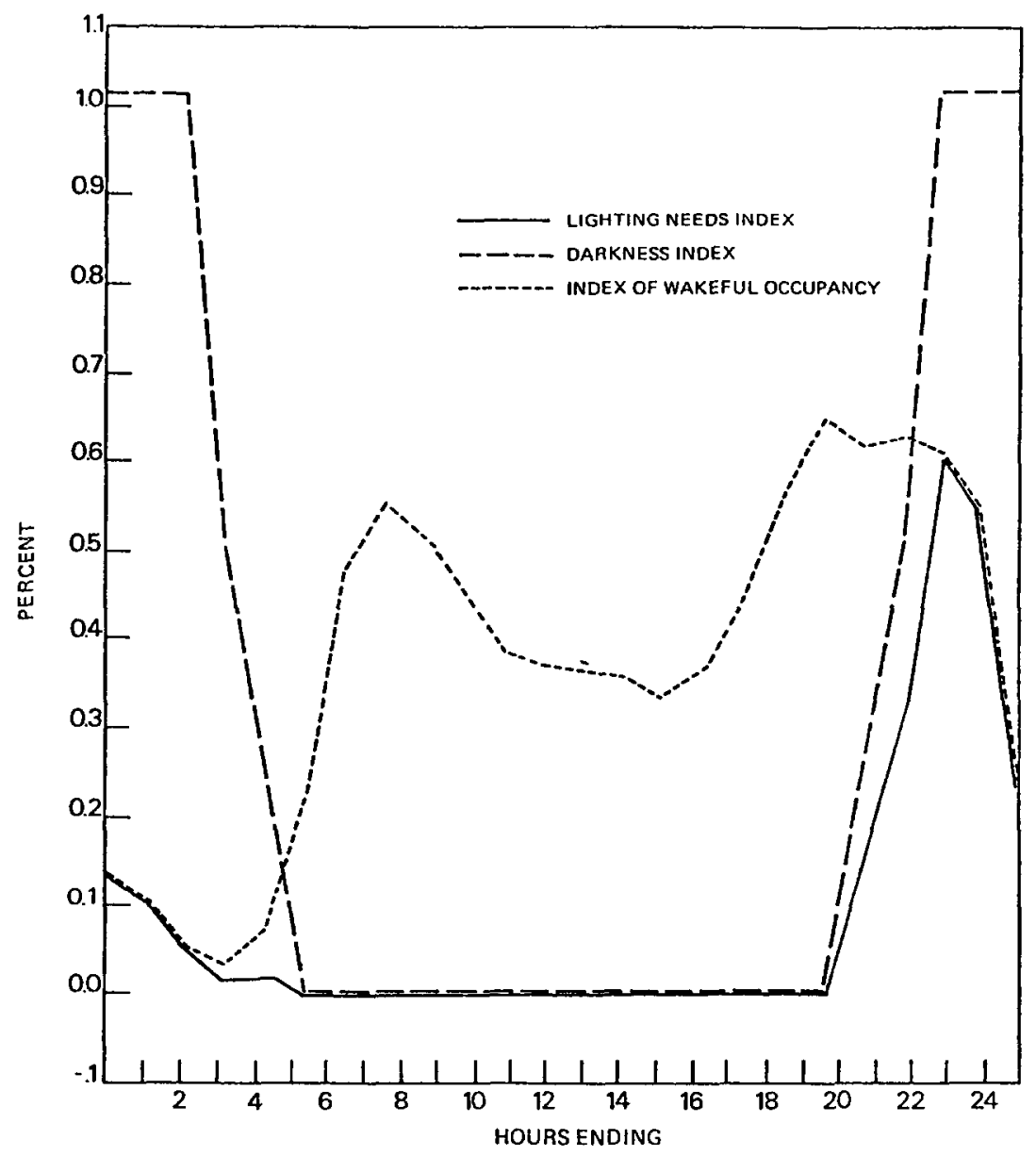

Fig. 5. Lighting needs index. 
4. Assessing the relative importance of various home activities on the residential curve

There are a number of ways in which one might go about assessing the relative importance of the various home activities we have discussed on the residential load curve. Traditionally utility forecasters have used appliance usage data (generally collected by such groups as the Edison Institute based on 'typical' use patterns) and appliance stock saturation data to estimate rate of growth of average and peak demands. This procedure is inadequate in that it generally ignores the tremendous variation in actual consumption from identical appliances due to the fact that individual households exercise considerable control over the timing and intensity of appliance usage. Because of the extent of this individual variability a superior method would be to relate actual household electricity demands by time-of-day to the pattern of activities conducted in the home and to the space conditioning needs at the individual level. Unfortunately, there is not as yet, nor is there likely to be in the forseeable future, a data set which combines detailed individual household consumption data with time-use data of sufficient quality to allow such an analysis.

As a compromise procedure, however, we can relate aggregate hourly demands of the residential sector to hourly levels of activities being conducted in the aggregate residential sector. Table 2 presents the various activities in order of declining relative statistical importance as measured by

\section{Table 2}

Regression results to illustrate the relative importance of various home activities in determining the residential load curve (average June weekday).

\begin{tabular}{|c|c|c|c|}
\hline \multirow{2}{*}{$\frac{\text { Activity }}{\text { Lighting }}$} & \multirow{2}{*}{$\begin{array}{c}\text { Partial } R \\
0.922\end{array}$} & \multicolumn{2}{|c|}{ Coefficient (standard error) } \\
\hline & & $6.487^{\mathrm{c}}$ & $(0.683)$ \\
\hline Dishwashing & 0.866 & $1.614^{c}$ & $(0.233)$ \\
\hline Laundry & 0.748 & $4.776^{c}$ & (1.058) \\
\hline Cooking & 0.699 & $0.905^{\mathrm{c}}$ & $(0.232)$ \\
\hline Bathing $\mathrm{a}^{\mathrm{a}}$ & 0.542 & $0.475^{c}$ & $(0.184)$ \\
\hline Housecleaning & -0.481 & $-1.548^{d}$ & $(0.704)$ \\
\hline Air conditioning ${ }^{b}$ & 0.464 & $0.394^{\mathrm{d}}$ & $(0.188)$ \\
\hline $\begin{array}{cr}R^{2}(\mathrm{adj}) & 0.964 \\
N & 24\end{array}$ & & & \\
\hline
\end{tabular}

"Variable is lagged one period because the principle component of electricity consumption is hot water which takes time to be replaced.

bVariable is defined as the square of the difference between actual hourly temperature and a presumed optimal temperature of 68 degrees Fahrenheit.

'Significant at the 0.05 level.

dSignificant at the 0.01 level. 
the partial $R^{2}$. The dependent variable in this analysis is hourly consumption for average June weekdays in 1975 (as a percent of the June residential peak) for a representative sample of Connecticut Power and Light Company's residential class whose dwellings were equipped with a special time-of-day meter. Since these customers are not likely to be representative of the United States residential population as a whole, as are the activity measures which comprise the independent variables, the results of this analysis should be viewed as tentative and suggestive rather than definitive.

Fig. 6 presents the actual load and the predicted load implied by the coefficients of table 2 for each hour of the day. As the high $R^{2}$ for the specification and similar shapes of the actual and predicted load curves in fig. 6 attest, the specification of the statistical model does a very credible job of

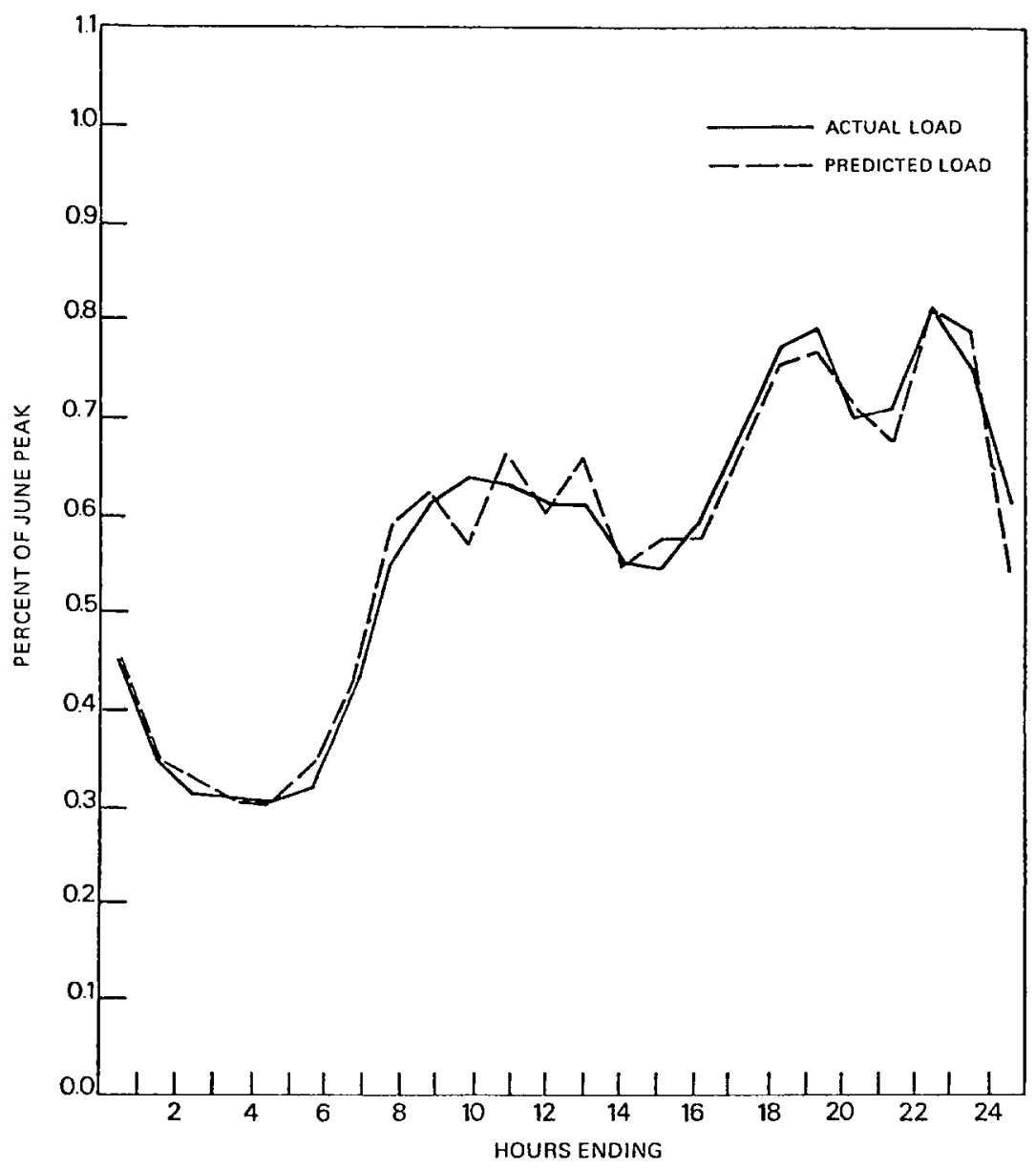

Fig. 6. Actual and predicted loads. 
explaining the hourly variation in electricity demands for these residential customers.

Perhaps the most surprising aspect of the results of this analysis is the apparently overwhelming importance of lighting loads in determining the shape of the June residential load curve, and the relative lack of importance of air conditioning loads. Part of the reason this result is surprising is perceptual. Air conditioning loads have been growing very rapidly over the last twenty years and we have not paid much attention to the fact that residential lighting accounts for a large fraction of total electricity consumption. ${ }^{4}$ While data on consumption by end use is far from perfect, lighting and small appliances (but primarily lighting) accounted for roughly seventeen percent of all electricity consumed in the United States in 1968 [see EPRI (1977b)], while air conditioning accounted for approximately twelve percent. It should be stressed, however, that the dependent variable in this analysis is hourly consumption for the average June day, and on average June is not a very hot month in the Northeastern United States. Had we used hourly loads for the day of the June system peak, or for average July days (data which was not available to this author), air conditioning would probably have appeared more important. It is also possible, of course, that simple thermal conduction is not the major mechanism by which heat flows into the home and therefore the air conditioning variable as defined leads to a misspecification of the model. It could also be that there are excluded variables which are correlated with the lighting index, such as television use, which result in an overstatement of the importance of lighting loads. These caveats should not be taken so seriously, however, as to be interpreted as saying that lighting is not an important contributor to the uneven load patterns faced by electric utilities. While individual light bulbs are generally small in terms of wattage, their use is often continuous over the several hours of the day in which they are needed, and typically people in households have numerous such individual bulbs on simultaneously.

As we have argued in the preceding sections, space conditioning and lighting loads are not well suited for load shifting because of the limited possibilities for and extreme expense of storage. Thus we would not expect these, the most important loads, to be very responsive to time-differentiated electricity 'prices. Households do, however, have discretion over the intensity of use of light bulbs and air conditioners, and thus there should be some response to higher peak prices in the form of conservation measures such as turning up the thermostat in the summer and turning off unneeded lights.

Next to lighting the most important loads in terms of partial $R^{2}$ are loads

\footnotetext{
${ }^{4} \mathrm{It}$ is interesting, however, to note that in the early days of electrification lighting loads were the only loads that electric utilities had to meet. It was only after the introduction of the electric iron, and the penetration of utility generated power in the industrial sector that utilities began to operate at all during daylight hours.
} 
associated with meals and laundry. Each point increase in the percent of households engaged in cooking meals is associated, on average, with a 0.9 percentage point increase toward the June residential peak, and a one point increase in the proportion of households doing dishes is associated with a 1.6 percentage point increase. While cooking, or more precisely the timing of meals, is likely to be subject to strong time-preference, and its intermediate product is not particularly well suited to storage, these considerations do not apply to dishwashing or to clothes washing. Thus, we would expect on a priori grounds that with properly designed time-differentiated electric rate structures there would be substantial shifts in peak loads resulting from shifts in dishwashing and laundry activities.

Bathing also appears to have some importance in determining residential load patterns, as does air conditioning. Each is sufficiently powerful to attain statistical significance at the 0.05 level of confidence.

The final variable, housecleaning, is interesting in that it exhibits a negative impact on the load curve. This is best interpreted as saying that housecleaning activities are so time intensive that they prevent people from engaging in more energy intensive activities. A properly designed rate program could perhaps encourage some shifting of this non-energy intensive home activity from off-peak rate periods to on-peak rate periods, although most of the activity seems to be concentrated in early morning mid-peak or shoulder periods.

It is interesting to note that so many of the activities which seem to contribute to the present state of residential load curves involve the use of hot water, and that hot water is their major energy component. This would suggest that a major response to time-of-day pricing in the long run would be the purchasing of large, timed electric hot water heaters rather than the currently fashionable small, fast recovery units. Alternatively, existing units could be placed on timers, and improvements in insulation made. With such a system people could continue to bathe and wash clothes when they want and still take advantage of the time-of-day rate structures. It is also interesting to note that such systems have been encouraged by some utilities, via reduced rates, but primarily by those utilities which face substantial competition from natural gas.

\section{Conclusions and directions for future research}

In trying to understand the residential demand for electricity by time-ofday, it is useful to view the residential load curve as consisting of the combined demands for electricity used in the production of various home commodities. In understanding the timing of these demands it is more fruitful to assume that households act as if they derive utility from intermediate goods produced with inputs of electricity and other com- 
modities than it would be, for instance, to assume that households behave as if they are maximizing a transcendental logarithmic utility function. Under the former assumption it is reasonable to assume that the timing of productive activities in the home is conditioned by time-preference for consumption (which is in turn impinged upon by institutionally fixed schedules) and often follows a pattern similar to that dictated by inventory adjustment models of the Ss type. Within this class of activities, those with long re-order cycles are considered to be more responsive to time-of-day pricing than are those with very short re-order cycles.

Given these conclusions, several a priori comments can be made on the likely impacts of various time-of-day pricing policies. The likelihood that households will find it advantageous to shift a given load is directly proportional to the length of the normal re-order cycle for the intermediate good involved, the amount of electrical energy involved in producing this intermediate good, the difference between peak and off-peak prices, and the marginal utility of discretionary income. Furthermore, the likelihood of shifting loads is expected to be inversely proportional to the subjective costs of having too few or too many of the intermediate goods on hand, as well as to the length of the peak price period. A final conclusion based on a priori conclusions is that the advantages of shifting loads to off-peak periods are affected by the instantaneous marginal utility of income at the time when peak prices cease (or begin) to be in effect, and therefore shifting behavior will be affected by the precise scheduling of the price periods.

Data from a variety of sources, primarily the National Time-Use Study, suggest that lighting and water heating loads are of primary importance in determining June load patterns within the residential sector. Many activities which require substantial inputs of hot water have relatively long re-order cycles. The possibilities for substitution across time periods for these activities in response to time-of-day rate structures are high in both the short- and long-run. Partly as a result of the unit of analysis (hourly demand on average June weekdays) air conditioning loads have less dramatic effects on the level of hourly demand. Had we used hourly loads and temperatures on the day of system peak these loads may have appeared more important.

Having established the importance of the timing of household activities in determining the residential load curve, the next phases of analysis should involve investigating the strength and determinants of time preference for these activities. Such an investigation will require household level data on work schedules of all family members, income, commuting distances, modes of travel, appliance stock characteristics, and a host of other measures not currently available. Other data which would be helpful in such an analysis is data on the actual time-of-day demands for electricity of individual households on various time-of-day rate schedules, coupled with detailed time diary data. Only after these data are analyzed can we be sure that hourly 
load forecasting models are appropriately specified and that the results of statistical procedures are reliable.

\section{References}

Atkinson, Scotl F., 1977, Responsiveness to lime-of-day electricity pricing: First empirical results, in: A. Lawrence, ed., Forecasting and modeling time-of-day and seasonal electricity demands (Electric Power Research Institute, Palo Alto, CA).

Atkinson, Scott E., 1978, A comparative analysis of response to time-of-day electricity pricing: Arizona and Wisconsin, in: D. Aigner, ed., Modeling and the analysis of electricity demand by time-of-day (Palo Alto, CA).

Christensen, Laurits and Douglas Caves, 1978, Econometric analysis of the Wisconsin residential TOU electricity experiment, in: D. Aigner, ed., Modeling and analysis of electricity demand by time-of-day (Palo Alto, CA).

EPRI, 1977a, Forecasting and modeling time-of-day and seasonal electricity demands, $A$. Lawrence, ed. (Electric Power Research Institute, Palo Alto, CA).

EPRI, 1977b, The residential demand for energy estimates of residential stocks of energy using capital, Vol. II (Electric Power Research Institute, Palo Alto, CA).

Karlin, $\mathrm{O}$ and K.J. Arrow, 1958, Studies in mathematical theory of inventory and production (Stanford University Press, Stanford, CA).

Koenker, Roger, 1977, Optimal peak load pricing with time-additive consumer preferences, in: A. Lawrence, ed., Forecasting and modeling time-of-day and seasonal electricity demands (Electric Power Research Institute, Palo Alto, CA).

Shepherd, W.G., 1966, Marginal-cost pricing in American utilities, Southern Economic Journal XXXIII, July.

Taylor, L.D., 1977, On modeling the residential demand for electricity by time-of-day, in: A. Lawrence, ed., Forecasting and modeling time-of-day and seasonal electricity demands (Electric Power Research Institute, Palo Alto, CA).

Turvey, R., 1968, Optimal pricing and investment in electricity (George, Allen and Unwin, London). 